\title{
Fauna y microflora edáfica asociada a diferentes usos de suelo
}

\section{Edaphic fauna and microflora associated with different land uses}

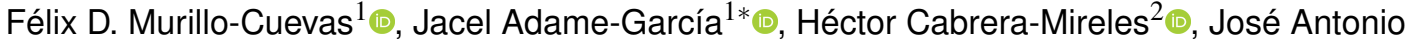 \\ Fernández-Viveros ${ }^{1}$ (D)
${ }^{1}$ Tecnológico Nacional de México-Instituto Tecnológico de Úrsulo Galván, km 4.5 Carr. Cardel-Chachalacas, CP. 91667. Úrsulo Galván, Veracruz, México.
${ }^{2}$ Instituto Nacional de Investigaciones Forestales, Agrícolas y Pecuarias, CIRGOC, Campo Experimental Cotaxtla, km. 34.5 carretera Federal Veracruz-Córdoba, CP. 94992. Medellín de Bravo, Veracruz, México.
*Autor de correspondencia: jadameg@gmail.com

Artículo científico recibido: 10 de abril de 2018 aceptado: 03 de octubre de 2018

RESUMEN. Con el objetivo de evaluar los efectos del uso de suelo con caña de azúcar y pastos, sobre la macrofauna, mesofauna y microflora en el municipio de Úrsulo Galván, Veracruz, se comparó la abundancia, riqueza y diversidad de grupos de organismos en suelo con caña, pasto y vegetación nativa típica de la región. Se utilizaron muestras de suelo tomadas con un cuadrante de $25 \times 25 \mathrm{~cm}$ a profundidad de $0-30 \mathrm{~cm}$, de los que se extrajo la fauna y microflora edáfica, para identificarla y cuantificarla. Los resultados indican que el suelo con caña de azúcar fue menos nocivo para la fauna edáfica (9 taxones y 305 individuos) que el suelo con pasto ( 6 taxones y 91 individuos) y que no fue diferente estadísticamente con el suelo con vegetación nativa (9 taxones y 357 individuos). La abundancia de la mayoría de los grupos de macro y mesofauna correspondieron a suelo con vegetación nativa (Aranea, Formicidae, Diplopoda y Oligochaeta) y con caña de azúcar (Isoptera, Chilopoda y Diplura). En la época de secas, el suelo con caña de azúcar registró la mayor abundancia de bacterias solubilizadoras de fósforo y fijadoras de nitrógeno (12333 ufc y 9465 ufc, respectivamente) en comparación con el suelo con vegetación nativa (4840 ufc y 5774 ufc, respectivamente). Únicamente el suelo cubierto con caña de azúcar tiene nula afectación sobre la fauna y flora microbiana del suelo.

Palabras clave: Biota edáfica, hormigas, Oligochaeta, Pseudomonas, termitas

ABSTRACT. In order to evaluate the effects of land use with sugarcane and grasses on macrofauna, mesofauna and microflora in the municipality of Úrsulo Galván, Veracruz, we compared the abundance, richness and diversity of groups of organisms in soil with sugarcane, grass and native vegetation typical of the region. Soil samples were taken from a $25 \times 25$ $\mathrm{cm}$ quadrant at a depth of 0-30 cm, from which soil fauna and microflora were extracted to identify and quantify them. Results indicate that soil with sugarcane was less harmful to soil fauna (9 taxa and 305 individuals) than soil with grass (6 taxa and 91 individuals) and that it was not statistically different from soil with native vegetation ( 9 taxa and 357 individuals). The abundance of most of the macro and mesofauna groups corresponded to soil with native vegetation (Aranea, Formicidae, Diplopoda and Oligochaeta) and with sugarcane (Isoptera, Chilopoda y Diplura). In the dry season, soil with sugarcane recorded the highest abundance of phosphorus-solubilizing and nitrogen-fixing bacteria (12333 cfu and $9465 \mathrm{cfu}$, respectively) compared to soil with native vegetation (4840 cfc and $5774 \mathrm{cfu}$, respectively). Only the soil covered with sugarcane has no effect on the soil's microbial flora and fauna.

Key words: Edaphic biota, ants, Oligochaeta, Pseudomonas, termites.

\section{INTRODUCCIÓN}

La macrofauna del suelo es diversa, abundante y multifuncional (Franco et al. 2016); las hormigas, termitas, escarabajos, seudoescorpiones, arañas, y otros grupos menos conocidos son abundantes e importantes para el funcionamiento del suelo, los cuales influyen en los procesos de descomposición y 
mineralización de nutrientes (Lang-Ovalle et al. 2011, Franco et al. 2016). La mesofauna es más abundante y diversa, siendo los ácaros y colémbolos los más importantes por su abundancia, diversidad y función en el suelo, además de que son indicadores ecológicos por su gran aptitud para la especiación, ciclos de vida corto y poca dispersión de las especies (Eeva y Penttinen 2009). Mientras que las comunidades microbianas son los componentes funcionales más importante de la biota del suelo, ya que juegan un papel importante en el flujo de energía, transformación de nutrientes y reciclaje de elementos (Souza et al. 2012, Stechauner y Madriñán 2013).

El uso de suelo asociado a la producción agrícola y ganadera es uno de los factores claves que afecta la biodiversidad edáfica, con impactos negativos en las propiedades físicas, químicas y biológicas, provocando disminución o pérdida de suelo (Cabrera et al. 2011b, Desiree et al. 2014, Franco et al. 2016). El estado de Veracruz, México, es el principal productor nacional de caña de azúcar con 247289.25 ha sembradas y producción de $17254324.59 \mathrm{t}$ con rendimiento promedio de 70.26 t ha ${ }^{-1}$ (SIAP 2018). El estado también tiene cerca de 3.7 millones de hectáreas de pastizales, que se dedican a la producción ganadera extensiva (SIAP 2018a). En la región centro del estado desde hace más de cincuenta años ha ocurrido un cambio de uso de suelo, de áreas de vegetación nativa a agrícolas o pastizales, y de cultivos de bajos insumos a cultivos de altos niveles de insumos sintéticos como la caña de azúcar (Saccharum officinarum L.) (Gobierno del Estado de Veracruz 2011). Municipios como Úrsulo Galván, tienen casi el $50 \%$ de su suelo para el cultivo de caña de azúcar, $23 \%$ para pastizales y sólo $6 \%$ para vegetación nativa, lo que tiene posibles impactos negativos en la calidad del suelo (INAP 2013).

La fauna y microflora edáfica se utilizan como bioindicadores de la calidad del suelo y para determinar el grado de recuperación o degradación del mismo (Pascual-Córdova et al. 2018). Se tienen antecedentes de efectos negativos del cultivo de caña de azúcar en la abundancia, riqueza y diversidad de la fauna edáfica (Franco et al. 2016). También se indica que la quema de caña de azúcar afecta las propiedades microbiológicas del suelo y la fertilidad (Souza et al. 2012). También se ha reportado efecto negativo de la caña de azúcar sobre artrópodos asociados al follaje y arvenses (Cabrera et al. 2011a), así como sobre la diversidad de macro y microfauna de artrópodos del suelo (Cabrera et al. 2009, Murillo et al. 2009). Sin embargo, también se ha señalado que las lombrices, termitas y miriápodos, son tolerantes a las condiciones de manejo de la caña de azúcar, lo que ha permitido que al comparar este cultivo con otros de bajos insumos como el mango, no se encuentren diferencias significativas en la incidencia y abundancia de la macrofauna edáfica (Lang-Ovalle et al. 2011). También se ha reportado una importante biomasa de lombrices (82\%), frecuencia de hormigas $(52 \%)$ y densidad de organismos (3000 individuos $\mathrm{m}^{2}$ ) en caña de azúcar (Brown et al. 2001).

En el municipio de Úrsulo Galván, Veracruz, la producción de caña de azúcar es una de las actividades productivas más importantes para la región, lo que justifica su permanencia y expansión, y el cultivo de pasto está ampliando cada vez más su frontera agrícola, por lo que es necesario documentar si en las condiciones actuales existen efectos negativos 0 no de estos cultivos, por lo anterior el objetivo del presente trabajo fue determinar el efecto del uso de suelo con caña de azúcar y pasto, utilizando a la fauna y microflora edáfica como bioindicadores de calidad o degradación del suelo y comparándolos con un suelo con vegetación nativa.

\section{MATERIALES Y MÉTODOS}

\section{Área de estudio}

Los sitios de muestreo se establecieron en terrenos del Instituto Tecnológico de Úrsulo Galván (ITUG) en el 2017, los cuales se encuentran ubicados en los $19^{\circ} 24^{\prime} 43.13^{\prime \prime}$ LN y 96 $21^{\circ} 32.61^{\prime \prime}$ LO, en el municipio de Úrsulo Galván, Veracruz, México.

\section{Diseño experimental}

Se ubicaron tres tipos de uso de suelo, los cuales fueron: con cultivo de caña de azúcar por 30 años, con la variedad ATEMEX-9640, pasto Mombasa (Panicum maximun cv. Mom- 
basa) (con 10 años, y vegetación nativa (sin cultivo) que corresponde a un fragmento de paisaje natural característico de la zona centro costera del estado de Veracruz, con predominancia de algodoncillo (Luehea candida Mart.), berenjena silvestre (Solanum torvum Sw.), bromelia (Bromelia pinguin L.), chintel (Pithecellobium dulce Roxb.), ciruelillo (Trichilia havanensis Jacq.), cocuite (Gliricidia sepium Jacq.), cornezuelo (Acacia cornígera L.), cruceta (Acanthocereus tetragonus L.), crucetillo (Randia monantha Benth.), cundeamor (Momordica charantia L.), cycada (Acacia cochliacantha Willd.), guazamo (Guazuma ulmifolia Lam.), leucaena (Leucaena leucocephala Lam.), necaxtle (Enterobolium cyclocarpum Jacq.), orquídea terrestre (Oececlades maculata Lindl.), palma de coyol (Acrocomia mexicana Jacq.), palo mulato (Bursera simaruba L.), piñón (Jatropha curcas L.), pionche (Bumelia selastrina Kunth.), tronadora (Wissadula amplissima L.), zarza bejuco (Anredera cordifolia Ten.), pica pica (Mucuna pruriens L.) y mimosa (Mimosa albida Willd.).

En cada área de uso de suelo se establecieron dos parcelas de $10 \mathrm{~m}^{2}$ a distancia aproximada de 15 $\mathrm{m}$ en caña de azúcar, $16 \mathrm{~m}$ en pasto y $60 \mathrm{~m}$ en suelo con vegetación nativa. Dentro de cada parcela, en cada uno de los usos de suelo, se establecieron dos puntos de muestreo, en los que con un cuadrante de $25 \times 25 \mathrm{~cm}$ se tomaron dos muestras de suelo a profundidad de $0-30 \mathrm{~cm}$, para lo cual se colectaron un total de ocho muestras por uso de suelo. Los muestreos se realizaron en dos épocas del año, en los meses abril-mayo y lluvias en los meses agostoseptiembre.

\section{Procesamiento de muestras}

Las muestras se procesaron en los Laboratorios de Entomología y Biología Molecular del ITUG. La extracción de la macro y mesofauna del suelo se realizó de forma manual y directa con charolas de plástico, pinzas entomológicas, pinceles, lupas y lentes de aumento. Los organismos extraídos se almacenaron en frascos con alcohol al $70 \%$ para su posterior identificación y conteo en un microscopio estereoscópico. Los organismos se identificaron a nivel de Orden, Clase, Subclase y algunas Familias taxonómicas con las claves de Triplehorn y Johnson (2005). De las muestras de suelo se tomaron 10 $\mathrm{g}$ para el conteo de unidades formadoras de colonias (UFC) de bacterias benéficas, para lo cual las muestras se procesaron con el método de dilución en placa. Para lo cual se colocarán $10 \mathrm{~g}$ de suelo en un matraz Erlenmeyer de $250 \mathrm{~mL}$, y se adicionaron $90 \mathrm{~mL}$ de solución estéril de fosfatos $\left(\mathrm{KH}_{2} \mathrm{PO}_{4} 0.25\right.$ $\mathrm{M})$. La solución se agitó a $120 \mathrm{rpm}$ durante $10 \mathrm{~min}$ en un agitador orbital (Shel $\mathrm{Lab}^{\mathrm{B}}$ ) y se prepararon seis diluciones entre $10^{-2}$ y $10^{-7}$. Las diluciones se dispersaron $0.1 \mathrm{~mL}$ sobre el medio de cultivo específico: agar nutritivo, para Pseudomonas agar A de King pH 7.2 (20 g peptona de carne, $1.4 \mathrm{~g}$ $\mathrm{MgCl}_{2}, 10 \mathrm{~g} \mathrm{~K}_{2} \mathrm{SO}_{4}, 13 \mathrm{~g}$ agar) para bacterias fijadoras de nitrógeno medio de cultivo ELMARC $\mathrm{pH} 6.8$ a 7.0 (5 g manitol, $0.2 \mathrm{~g}$ extracto de levadura, $0.25 \mathrm{~g}$ $\mathrm{k}_{2} \mathrm{HPO}_{4}, 0.1 \mathrm{~g} \mathrm{MgSO}_{4} 7 \mathrm{H}_{2} \mathrm{O}, 0.05 \mathrm{~g} \mathrm{NaCl}, 1: 400$ rojo de Congo, $18 \mathrm{~g}$ agar) y bacterias solubilizadoforas de fósforo medio de cultivo SRSM pH $7.2(0.25 \mathrm{~g}$, $\left(\mathrm{NH}_{4}\right) 2 \mathrm{SO}_{4}, 0.1 \mathrm{~g} \mathrm{KCl}, 0.15 \mathrm{~g} \mathrm{MgSO}_{4} \mathrm{H}_{2} \mathrm{O}, 0.002 \mathrm{~g}$ $\mathrm{FeSO}_{4} 7 \mathrm{H}_{2} \mathrm{O}, 0.1 \mathrm{~g} \mathrm{NaCl}, 5 \mathrm{~g}$ glucosa, $0.25 \mathrm{~g}$ extracto de levadura, $0.05 \mathrm{~g}$ de purpura de bromocresol, $2.5 \mathrm{~g}$ $\mathrm{Ca}_{3}\left(\mathrm{PO}_{4}\right) 2,7.5 \mathrm{~g}$ agar) y se incubaron a $30 \pm 1{ }^{\circ} \mathrm{C}$ durante $24 \mathrm{~h}$. La siembra se realizó por triplicado, una vez que transcurrió el tiempo se contaron las colonias desarrolladas.

\section{Análisis de datos}

Se calculó la abundancia de los organismos y microorganismos, con el número de individuos y unidades formadoras de colonias (UFC), respectivamente. También se determinó la riqueza (número de grupos) y diversidad (índice de Shannon $\left(H^{\prime}\right)$ ) de la macro y mesofauna con el programa EstimateS versión 8.2.0. Comunidades de macrofauna, mesofauna y bacterias se agruparon de acuerdo a sus correspondencias con los usos de suelos con un análisis de correspondencia simple (AC). Se utilizó la prueba no paramétrica de Kruskal-Wallis para probar el efecto del uso del suelo y época del año. Se realizó un análisis de efectos mixtos lineal de la relación entre las variables individuales de los organismos (abundancia, riqueza y diversidad) y el uso del suelo. Como efectos fijos, se utilizó el uso del suelo y la época 

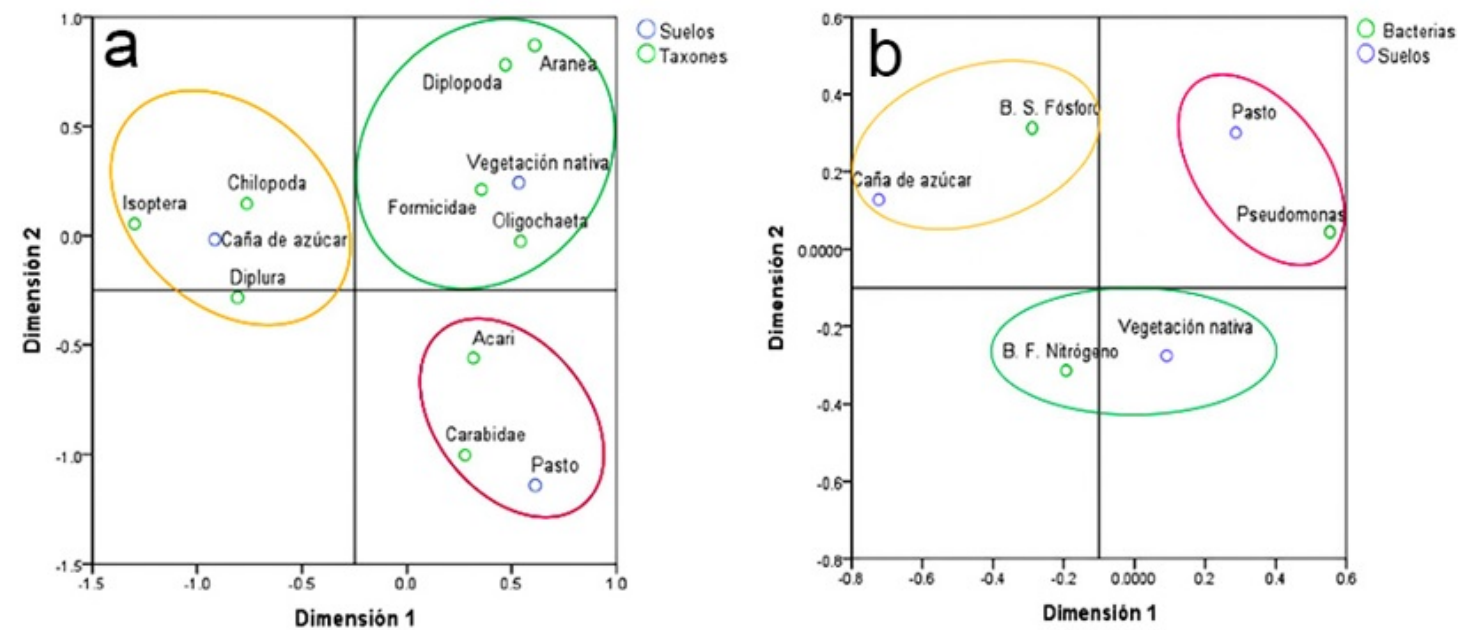

Figura 1. Escala dimensional del análisis de correspondencia entre usos de suelo y la fauna edáfica (a) y bacterias del suelo (b).

del año en el modelo, y como efectos aleatorios, las parcelas. Todos los análisis se realizaron con el programa IBM SPSS Statistics 20.

\section{RESULTADOS}

Las comunidades de macrofauna, mesofauna y bacterias del suelo de caña de azúcar, pasto y vegetación nativa se separaron en la escala dimensional del AC (Figura 1). Lo que sugiere que los grupos de organismos y microorganismos variaron entre usos de suelo. Mientras que la mayoría de los grupos de macro y mesofauna se encontraron en el suelo con vegetación nativa, mientras que grupos como Isoptera, Chilopoda y Diplura se encuentran en suelo con caña de azúcar (Figura 1a). Para las bacterias los grupos se separaron por sus funciones, el suelo con caña de azúcar tuvo mayor población de bacterias solubilizadoras de fósforo en comparación al suelo con vegetación nativa, que tuvo mayor contenido de bacterias fijadoras de nitrógeno (Figura 1b). El suelo con pasto tuvo menos grupos taxonómicos de Pseudomonas, las diferencias en la composición de la macro y mesofauna entre los usos de suelo, así como de los grupos de bacterias, se confirmó con la prueba de Kruskal-Wallis $\left(\mathrm{df}=2, \mathrm{X}^{2}=20.3\right.$, $\mathrm{p}$ $=0.0001 ; \mathrm{df}=2, \mathrm{X}^{2}=11.1, \mathrm{p}=0.004$, respectivamen- te), que también demostró un efecto significativo de la época del año ( $d f=1, X^{2}=18.9, p=0.0001$; $d f$ $=1, X^{2}=40.8, p=0.0001$ ) en la abundancia de los grupos de organismos y microorganismos, lo que significa que las diferentes condiciones del suelo y clima juegan un papel determinante para la presencia 0 ausencia de grupos específicos de organismos.

El análisis de efectos mixtos lineales mostró que el uso del suelo y época del año afectaron la abundancia total $\left(F_{2,72}=8.8, p=0.0001 ; F_{2,72}=8.5\right.$, $\mathrm{p}=0.0001)$ y riqueza de taxones $\left(\mathrm{F}_{2,72}=8.8, \mathrm{p}=\right.$ $0.0001 ; F_{2,72}=16.0, p=0.0001$ ) de la macro y mesofauna en la época de lluvias, y no hubo efectos significativos en el índice de diversidad para uso de suelo $\left(F_{2,72}=2.0, p=0.139\right)$, pero si para la época del año $\left(F_{2,72}=10.1, p=0.0001\right)$. En la época de lluvias, hubo un incremento promedio de 21.7 individuos en el suelo con caña de azúcar en relación con el suelo con pasto y sin efecto aparente en relación al suelo con vegetación nativa (Figura 2a). Se identificaron nueve taxones de macro y mesofauna del suelo con vegetación nativa y caña de azúcar, mientras que en suelo con pasto se identificaron seis taxones (Tabla 1).

Los suelos con vegetación nativa y caña de azúcar tuvieron en promedio el mayor número de taxones $(7.1 \pm 1.9$ y $6.8 \pm 2.8)$ (Figura $2 b)$. Las 

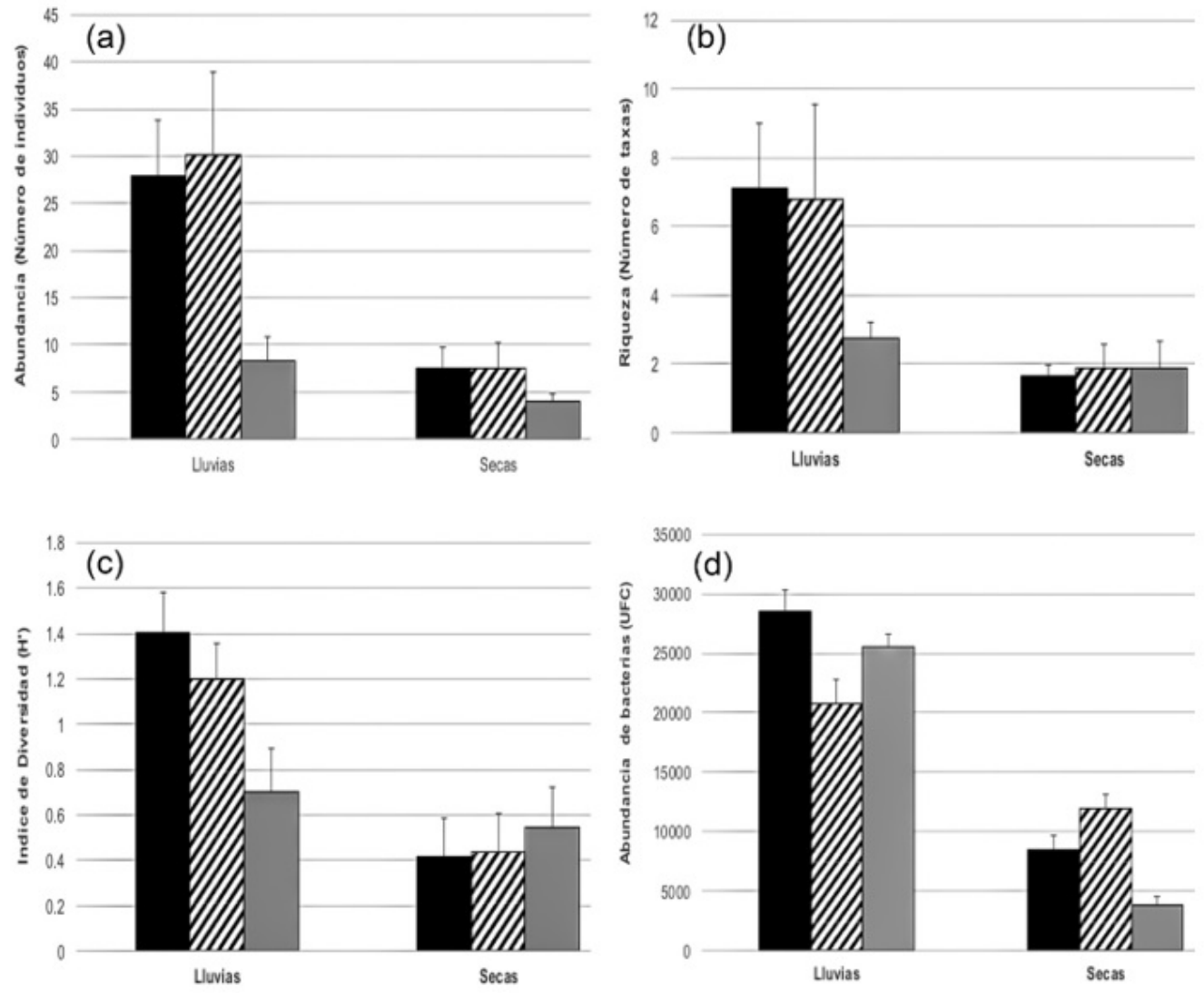

Figura 2. Abundancia (a), riqueza (b) y diversidad (c) de fauna edáfica y abundancia (d) de bacterias edáficas a una profundidad de 0-30 $\mathrm{cm}$ como una función del uso de suelo. $\mathrm{n}=8$, las barras de error denotan el error estándar de la media.

mayores abundancias por taxones se observaron en Oligochaeta (lombriz de tierra), Formicidae (hormigas), Isoptera (termitas) y Carabidae (escarabajos) (Tabla 1). Las lombrices abundaron más en la época de lluvias en suelo con vegetación nativa, con $67 \%$ más individuos que en caña de azúcar y $68 \%$ en pasto. Las hormigas fueron abundantes en las dos épocas del año en suelo con vegetación nativa, seguido por caña de azúcar y pasto, con porcentajes de abundancia del 54, 35 y $11 \%$, respectivamente. El suelo con caña de azúcar registró la mayor abundancia de termitas en las dos épocas del año, con 73 y 100\% más individuos totales que en vegetación nativa y pasto, respectivamente. Los escarabajos fueron más abundantes en lluvias en suelo con vegetación nativa. Para la abundancia total de bacterias edáficas, el análisis de efectos mixtos lineales mostró diferencias entre los usos de suelo $\left(F_{2,72}=5.7, p=0.005\right)$ y época del año $\left(F_{2,72}=\right.$ 1378.2, $p=0.0001$ ), siendo en promedio mayor en suelo con vegetación nativa (28507 \pm 1797 ufc) en la época de lluvias y en suelo con caña de azúcar (11874 \pm 1246 ufc) en la época se secas (Figura 2c). El suelo con caña de azúcar registró la menor cantidad de bacterias Pseudomonas, con 22667 UFC menos que en pasto y 22023 UFC menos que en vegetación nativa (Tabla 2). La época de lluvias benefició la abundancia de bacterias fijadoras de nitrógeno y solubilizadoras de fósforo en suelo con vegetación nativa, mientras que en secas estas bacterias fueron más abundantes en suelo con pasto (13 464 UFC) y caña de azúcar (12 333 UFC). 

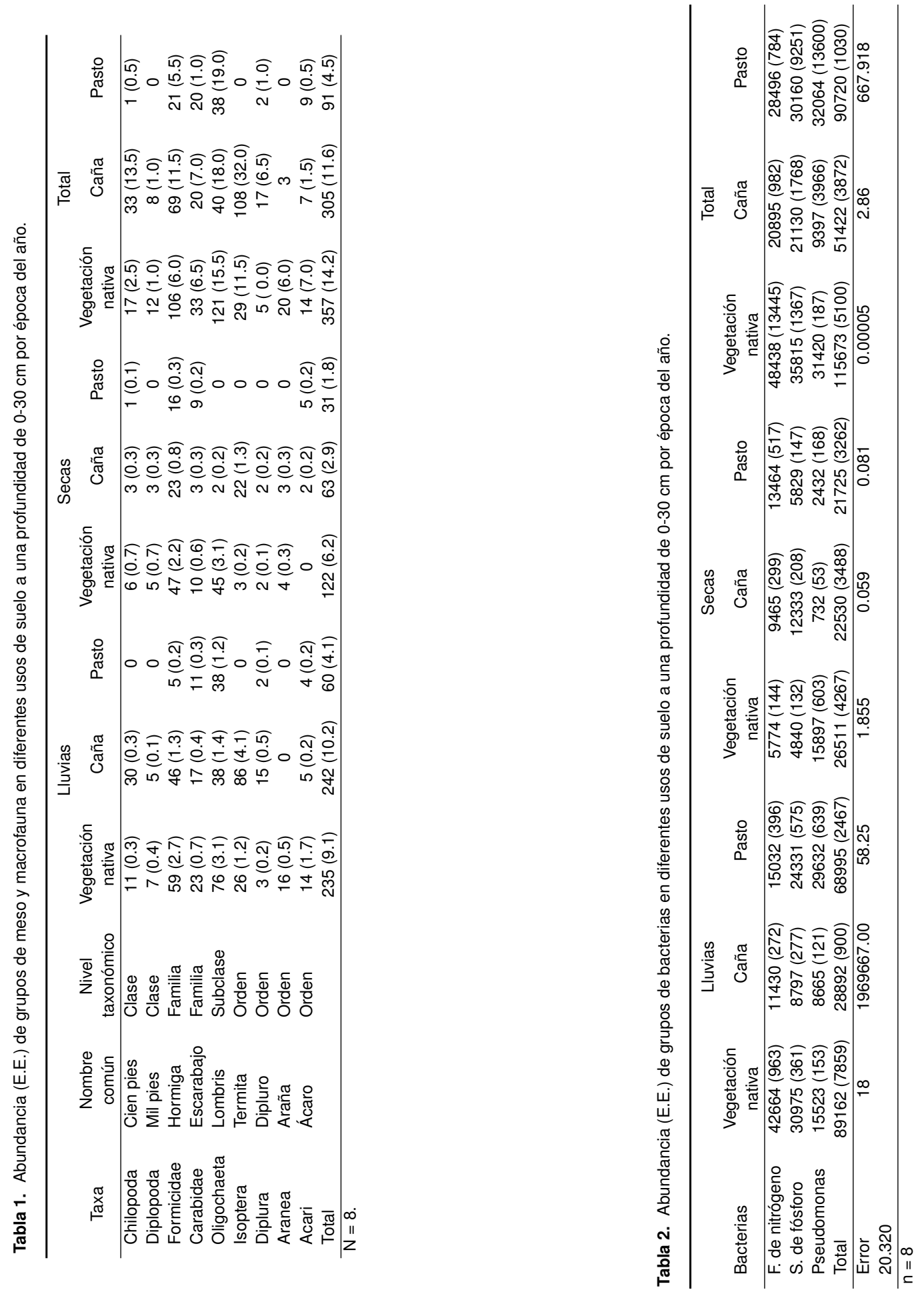


\section{DISCUSIÓN}

La abundancia, riqueza y diversidad de organismos encontrados en cada uno de los usos de suelo, permitió inferir que el uso de suelo o tipo de agroecosistema afecta de forma significativa la fauna y microflora edáfica. Pero también permitió conocer que los usos de suelo con caña de azúcar y vegetación nativa compartieron un número alto de organismos y taxones. Los sistemas estudiados poseen cierto grado de intervención o alteración por el hombre, vegetación nativa intervenida, caña de azúcar con laboreo agrícola y pastizales con manejo ganadero, donde pueden colonizar taxones con características semejantes de tolerancia, adaptables y resistentes a las perturbaciones inducidas, como lo reporta Cabrera et al. (2011b). Algunos organismos como las hormigas y las termitas son ejemplos de taxones con características semejantes de tolerancia a condiciones de perturbación, lo que permite que estos organismos sean abundantes y diversos en diferentes gradientes de intensidad de manejo de uso de suelo (Morales-Vásquez et al. 2014).

La abundancia de lombrices fue significativamente menor en el cultivo de caña y pasto, debido a un mayor laboreo del suelo y uso de agroquímicos, siendo este grupo uno de los principales indicadores de degradación del suelo (Sánchez y Hernández 2011). Pero hubo otros grupos de organismos como las termitas (Isoptera), cien pies (Chilopoda) y dipluros (Diplura) que fueron más abundantes en el suelo con caña de azúcar, probablemente para las características del cultivo de la caña de azúcar, ya que se tiene la hipótesis de que en el cultivo de caña persistente se presenta mayor estabilidad poblacional de fauna edáfica, con respecto a caña reciente, debido a que los organismos se encuentran adaptados a ambientes perturbados. Lo que puede explicar la similitud en abundancia, riqueza y diversidad de la meso y macrofauna en vegetación nativa y en caña de azúcar, y coincide con lo reportado por Lang-Ovalle et al. (2011) quienes indican similitud en diversidad y riqueza de macrofauna en mango y caña. Mientras que Barajas-Guzmán y Álvarez-
Sánchez (2003), reportan nula variación de riqueza taxonómica de fauna entre diferentes ambientes. La similitud de la abundancia, riqueza y diversidad de macro y mesofauna entre suelos con vegetación nativa y caña de azúcar indica buen estado de conservación del suelo con caña de azúcar, a diferencia del suelo con pasto. Las comunidades biológicas funcionales presentes en el suelo con caña de azúcar están representadas por detritívoros, descomponedores y depredadores, las cuales en poblaciones dinámicamente estables favorecen cambios en las propiedades físicas y químicas del suelo. Por ejemplo, las termitas, se asocian con el ciclo del carbono y con el nivel de la fertilidad del suelo (Jones 1990), pero también se han reportado como plagas (Méndez y Equihua 2001, Hurtado-Borrero et al. 2017). Las lombrices mejoran la estructura y porosidad del suelo y reducen la pérdida de nitrógeno (Domínguez et al. 2009), mientras que las hormigas, ácaros, milpiés, ciempiés y arañas son depredadores que mantienen o restauran la calidad del suelo (Huhta 2007).

Los suelos con vegetación nativa fueron más diversos en grupos de la macro y mesofauna, lo que sugiere mayor complejidad de grupos y funciones ecológicas en comparación con el pasto y en menor modo con caña de azúcar; por ejemplo, las hormigas, termitas y lombrices de tierra fueron los grupos más abundantes en suelos con vegetación nativa y caña de azúcar, como lo reportan Cabrera et al. (2009) y Batista et al. (2014). La presencia de termitas y lombrices de tierra en el suelo con caña de azúcar puede tener impactos positivos en la estabilidad estructural del suelo, ya que tienen la capacidad de moverse a través del suelo construyendo estructuras biogénicas estables en propiedades físicas, químicas y microbiológicas específicas (Jouquet et al. 2006). La diversidad de los grupos de macro y mesofauna que corresponden al suelo con pasto fue menor, incluida la pérdida de grupos depredadores (Araneae, Chilopoda y Formicidae) y detritívoros (Oligochaeta y Diplopoda). Este resultado está influenciado por la menor diversidad de plantas, pisoteo del ganado, compactación y erosión del suelo, características de un suelo con sobrepastoreo (Martínez et al. 2014). Pero otros estudios en caña de azúcar indican im- 
pacto negativo del cultivo al compararse con pasto y vegetación nativa (Cabrera et al. 2011a), esta diferencia en relación a lo reportado en el presente estudio puede deberse a las condiciones ambientales y los cultivos, lo que puede contribuir a los bajos valores de biodiversidad que se presentan, incluso en suelos con vegetación nativa (Franco et al. 2016). Para el estado de Veracruz, se reporta que los suelos con caña de azúcar persistente no afectan a la fauna edáfica (Lang-Ovalle et al. 2011), lo cual coincide con los resultados encontrados y contribuyen a la hipótesis que indica que algunos organismos pueden adaptarse a las condiciones del cultivo de caña de azúcar.

La época de secas impactó de forma negativa la abundancia, riqueza y diversidad de los organismos, contrariamente a lo que se ha reportado en insectos terrestres en sistemas de manejo de mango, en el que las lluvias afectan las comunidades de organismos (Cabrera et al. 2009). Es probable que, en los suelos estudiados, las condiciones de humedad o sequía tengan efecto en las condiciones físico químicas del suelo, lo que impacta en la biota edáfica, de forma positiva o negativa. También es posible que, debido a que organismos que habitan en el interior del suelo, sufran más los cambios físicos del suelo en la época de secas y estén más protegidos a las inclemencias de las lluvias o bajas temperaturas, situación contraria a organismos que habitan sobre el suelo, los cuales pueden ser afectados por el exceso de lluvias o bajas temperaturas (Cabrera et al. 2009).

El suelo con caña de azúcar mantuvo mejores condiciones para la microflora en la época de secas, en comparación con el suelo con vegetación nativa y pasto, lo que se puede deber a las características del cultivo, por ser este un cultivo de ciclo largo que acumula elevadas concentraciones de sacarosa durante el desarrollo vegetativo (Pérez y Casas 2005). Lo que permite que la colonización de la raíz por las bacterias benéficas esté relacionada con mayor disponibilidad de carbono y humedad en la rizósfera del cultivo. Aunado a esto, el movimiento microbiano se asocia con fenómenos como quimiotaxis, aerotaxis, adhesión y movimiento debido a la percolación y/o evaporación del agua (Loredo-Osti et al. 2004). En la caña de azúcar se han aislado un gran número de microorganismos diazótrofos de vida libre entre los que se encuentran las bacterias del género Azospirillum (Seshadri et al. 2000). En las gramíneas, como la caña de azúcar, la transferencia de nutrimentos del suelo hacia las células de la raíz se debe a una interfase mucilaginosa, compuesta principalmente de polisacáridos (Gregory y Hinsinger 1999). La raíz a través del suelo fija las partículas del suelo en contacto con el mucílago hacia la superficie de la raíz. El incremento de la viscosidad, tanto del suelo seco, como del mucílago deshidratado, mantienen las partículas del suelo en su lugar y facilita la formación de la envoltura de la raíz (Read et al. 1999), lo que genera un ambiente favorable para el desarrollo de las bacterias benéficas, debido a la presencia de fuentes de carbono y energía, las cuales se pueden originar por los exudados radicales y residuos vegetales que se depositan en el suelo (Pérez y Casas 2005).

El cambio de uso de suelo a pasto puede tener más impacto negativo que el cambio a caña de azúcar, ya que los pastizales causan cambios en las propiedades físicas del suelo por el pisoteo del ganado (Martínez et al. 2014), degradando la tierra por el sobrepastoreo, compactación por malas prácticas y erosión (Steinfeld et al. 2006). De tal forma que es necesario rediseñar los sistemas pastoriles a sistemas más amigables con el ambiente, tal como el sistema silvopastoril, que es una forma más sustentable de hacer ganadería y conservar la calidad del suelo (Haile et al. 2010, Palma y Anguiano 2015).

\section{CONCLUSIONES}

A pesar que la expansión del cultivo de caña de azúcar en el municipio de Úrsulo Galván es un factor que potencializa la pérdida de biodiversidad en la región, por las prácticas agrícolas intensivas y la reducción de áreas de vegetación nativa, los resultados indican que el uso de suelo con caña de azúcar no afecta a la fauna y flora microbiana del suelo, mientras que el suelo con pasto tuvo efecto negativo sobre estos. La época de secas es un factor limitante para la fauna y microflora edáfica en los usos de suelo, pero el cultivo de caña de azúcar per- 
mite condiciones que favorecen la microflora en estas condiciones, permitiendo en mayor contenido de microorganismos.

\section{AGRADECIMIENTOS}

Al Tecnológico Nacional de México por financiar el trabajo por medio del proyecto Institucional con clave 6218.17-P. A los estudiantes de Licenciatura en Biología y Agronomía del Instituto Tecnológico de Úrsulo Galván por el apoyo en el trabajo de campo y procesamiento de muestras.

\section{LITERATURA CITADA}

Barajas-Guzmán G, Álvarez-Sánchez J (2003) La comunidad desintegradora en una selva húmeda tropical. En: Álvarez SJ, Naranjo GE (eds.). Ecología del suelo en la selva tropical húmeda de México. Instituto de Ecología, Instituto de Biología y Facultad de Ciencias, UNAM. México. pp: 162-184.

Batista I, Correia MEF, Pereira MG, Bieluczyk W, Schiavo JA, Rouws JRC (2014) Oxidizable fractions of total organic carbon and soil macrofauna in a crop-livestock integration system. Revista Brasileira de Ciência do Solo 38: 797-809.

Brown GG, Fragoso C, Barois I, Rojas P, Patrón JC, Bueno J, et al. (2001) Diversidad funcional de la macrofauna edáfica en los ecosistemas tropicales mexicanos. Acta Zoológica Mexicana 1: 79-110.

Cabrera MH, Murillo CFD, Gutiérrez VHR, Yopihua PJ, Ortega ZDA, Villanueva JJA (2009) Abundancia y diversidad de artrópodos terrestres en sistemas de manejo de producción de mango Manila (Mangifera indica L.) en Veracruz. En: Barradas LH, Esqueda EV, Tosquy VOH, Vinay VJC, Zarate MJP, Hernández BA, et al. (ed). Avances en la Investigación Agrícola, Pecuaria, Forestal y Acuícola en el Trópico mexicano. Libro Científico Núm. 6. Veracruz, México. pp: 111-118.

Cabrera MH, Murillo CFD, Ortega ZDA, Villanueva JJA, Escobar DAA (2011a) Impact of mango Manila management systems on arthropods in foliage and weeds. Tropical and Subtropical Agroecosystems 13: 317-326.

Cabrera G, Robaina N, Ponce de León D (2011b) Riqueza y abundancia de la macrofauna edáfica en cuatro usos de la tierra en las provincias de Artemisa y Mayabeque, Cuba. Pastos y Forrajes 34: 313-330.

Desiree JI, Pita AV, Floor VDH, Andre PCF (2014) Biodiversity impacts of bioenergy crop production: a state-ofthe-art review. Global Change Biology Bioenergy 6: 183-209.

Domínguez J, Airam M, Gómez-Brandón M (2009) The role of earthworms on the decomposition of organic matter and nutrient cycling. Ecosistemas 18: 20-31.

Eeva T, Penttinen R (2009) Leg deformities of oribatid mites as an indicator of environmental pollution. Science of the Total Environment 407: 4771-4776.

Franco ALC, Bartz MLC, Cherubin MR, Baretta D, Cerri CEP, Feigl BJ, et al. (2016) Loss of soil (macro) fauna due to the expansion of Brazilian sugarcane acreage. Science of the Total Environment 563-564: 160-168.

Gobierno del Estado de Veracruz (2011) Plan Veracruzano de Desarrollo (2011-2016). Gobierno del Estado de Veracruz. Veracruz. 302p.

Gregory PJ, Hinsinger P (1999) New approaches to studying chemical and physical changes in the rhizosphere: An overview. Plant Soil 211: 1-9.

Haile SG, Nair VD, Nair PKR (2010) Contribution of trees to carbon storage in soils of silvopastoral system in Florida, USA. Global Change Biology 16: 427-438. 
Huhta V (2007) The role of soil fauna in ecosystems: A historical review. Pedobiologia 50: 489-495.

Hurtado-Borrero HY, Manga-Candelario DA, Sepúlveda-Cano PA (2017) Registro de termitas (Isoptera) asociadas a cultivos de mango (Mangifera indica) en el departamento del Magdalena, Colombia. Intropica 12: 109115.

INAP (2013) Diagnósticos Municipales PACMA, entidad: Veracruz de Ignacio de la Llave, Municipio: Úrsulo Galván. Instituto Nacional de Administración Pública. México 49p.

Jones JA (1990) Termites, soil fertility and carbon cycling in dry tropical Africa: A hypothesis. Journal of Tropical Ecology 6: 291-305.

Jouquet P, Dauber J, Lagerlof J, Lavelle P, Lepage M (2006) Soil invertebrates as ecosystem engineers: intended and accidental effects on soil and feedback loops. Applied Soil Ecology 32: 153-164.

Lang-Ovalle PF, Pérez-Vázquez A, Martínez-Dávila JP, Platas-Rosado DE, Ojeda-Enciso LA, González-Acuña IJ (2011) Macrofauna edáfica asociada a plantaciones de mango y caña de azúcar. Terra Latinoamerica 29: 169-177.

Loredo-Osti C, López-Reyes L, Espinosa-Victoria D (2004) Bacterias promotoras del crecimiento vegetal asociadas con gramíneas. Una revisión. Terra Latinoamericana 2: 225-239.

Martínez J, Cajas YS, León JD, Osorio NW (2014) Silvopastoral Systems Ehance Soil Quality in Grasslands of Colombia. Applied and Environmental Soil Science. Article ID 359736. Doi: 10.1155/2014/359736.

Méndez MJT, Equihua MA (2001) Diversidad y manejo de los termes de México (Hexapoda, Isoptera). Acta Zoológica Mexicana 1: 173-187.

Morales-Vásquez E, Miguel-Méndez RS, Vázquez-Xochipa A, Janelly-Barrientos-Roldan M, Gutiérrez-Carmona DE, Altamirano-Leal C (2014) Análisis de la diversidad de la macrofauna edáfica por estratos en dos usos de suelo en San Lorenzo Ometepec, Puebla. Entomología Mexicana 1: 514-518.

Murillo CFD, Cabrera MH, Yopihua PJ, Gutiérrez VHR, Ortega ZDA, Villanueva JJA (2009) Diversidad y abundancia de microartrópodos en sistemas de manejo de producción de mango Manila (Manguifera indica L.) en Veracruz. En: Barradas LH, Esqueda EV, Tosquy VOH, Vinay VJC, Zarate MJP, Hernández BA, et al. (ed). Avances en la Investigación Agrícola, Pecuaria, Forestal y Acuícola en el Trópico mexicano. Libro Científico Núm. 6. Veracruz, México. pp: 119-127.

Palma GJM, Anguiano CJM (2015) Sistemas silvopastoriles en el mejoramiento de los sistemas de producción bovina en ganadería de doble propósito en México. In: Núñez DR, Ramírez VR, Fernández RS, Araujo FO, García WM, Díaz MTE (ed.). La ganadería en América Latina y el Caribe: Alternativas para la producción competitiva, sustentable e incluyente de alimentos de origen animal. Biblioteca Básica de Agricultura. México. pp: 375-387.

Pascual-Córdova G, Obrador-Olán JJ, Carrillo-Ávila E, García-López E, Sánchez-Soto S, Guerrero-Peña A, et al. (2018) Indicadores de calidad del suelo en el agroecosistema caña de azúcar (Saccharum spp.). Revista Facultad de Agronomía 35: 1-25.

Pérez J, Casas M (2005) Estudio de la interacción planta-Azospirillum en el cultivo de caña de azúcar (Saccharum sp.). Cultivos Tropicales 26: 13-19.

Read DB, Gregory PJ, Bell AE (1999) Physical properties of axenic maize root mucilage. Plant Soil 211: 87-91.

Sánchez S, Hernández M (2011) Comportamiento de comunidades de lombrices de tierra en dos sistemas ganaderos. Pastos y Forrajes 34: 359-366. 
Seshadri S, Muthukumarasamy R, Lakshminarasimhan C, Ignacimuthu S (2000) Solubilization of inorganic phosphates by Azospirillum halopraeferans. Current Science 79: 565-567.

SIAP (2018) Servicio de Información Agroalimentaria y Pesquera. Anuario Estadístico de la Producción Agrícola, año 2002. SAGARPA. http://infosiap.siap.gob.mx/aagricola_siap_gb/icultivo/index.jsp. Fecha de consulta: 4 de abril de 2018.

SIAP (2018a) Servicio de Información Agroalimentaria y Pesquera. Anuario Estadístico de la Producción Pecuaria, año 2002. SAGARPA. http://infosiap.siap.gob.mx/apecuaria_siap_gb/icultivo/index.jsp. Fecha de consulta: 4 abril de 2018.

Souza RA, Telles TS, Machado W, Hungria M, Filho JT, Guimarães MF (2012) Effects of sugarcane harvesting with burning on the chemical and microbiological properties of the soil. Agriculture, Ecosystems \& Environment 155: 1-6.

Stechauner RR, Madriñán MR (2013) Interacción macrofauna-microbiota: Efectos de la transformación de residuos de cosecha sobre la actividad de $\beta$-glucosidasa edáfica. Biotecnología en el Sector Agropecuario y Agroindustrial 11: 184-195.

Steinfeld H, Gerber P, Wassenaar T, Castel V, Rosales M, de Haan C (2006) La larga sombra del ganado: Problemas ambientales y opciones. LEAD y FAO, Roma, Italia. 464p.

Triplehorn CA, Johnson NF (2005) Borror and delong's introduction to the study of insects. Reimpresión 2005. 7th Edition. Thomson Brooks/Cole. USA. 864p. 
